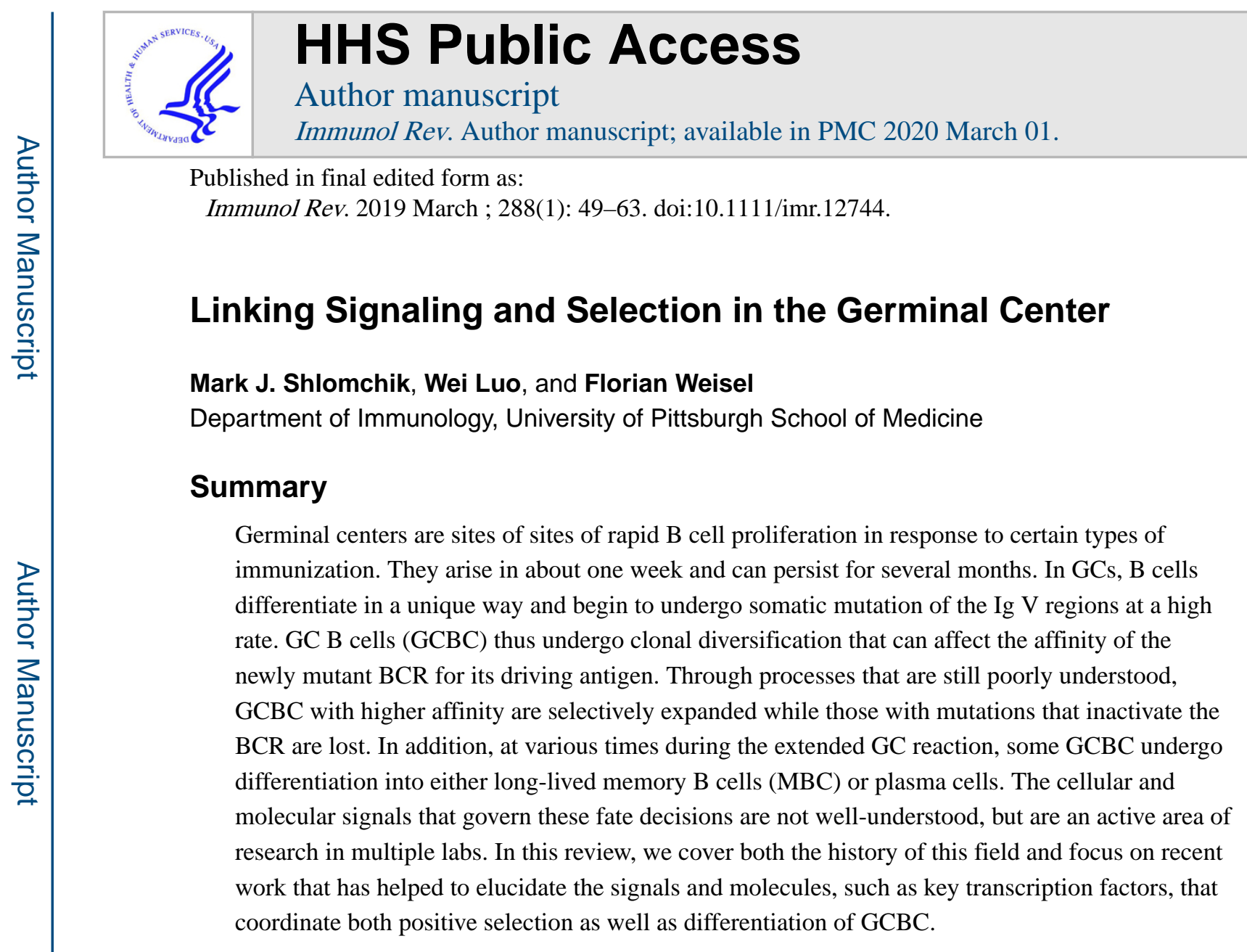

\title{
Introduction
}

This review will focus on new insights into how germinal center (GC) B cells (GCBC) are reprogrammed to undergo positive and negative selection, and how the process of differentiation into long-lived progeny is controlled. After an initial overview of the GC process as a whole, in order to provide context, the review will focus on GCBC and the selective processes that operate on them to generate populations of GCBC with increased affinity for Ag ("affinity maturation") yet without autoreactivity. Lastly, the progeny of GCBC that have differentiated into either long-lived memory B cells (MBC) or antibody forming cells (AFC) will be discussed.

\section{The purpose of the GC}

The Germinal Center (GC) reaction is elicited in B cell follicles of secondary lymphoid tissues in response to a variety of infections and immunization regimes. In GCs, B lineage cells differentiate into a unique state driven by a specific transcriptional program. These cells undergo intense proliferation along with somatic mutation of their B cell receptor (BCR) V regions, matched by a nearly equal rate of cell death. The purpose of this process is not to create immediate effector function - unlike other phases of adaptive $\mathrm{T}$ and $\mathrm{B}$ cell responses — but rather to select for mutants with higher affinity for antigen as well as to diversify the 
response from single clonotypes (i.e. progeny of single unmutated cells) to a family of clonotypes that have a single parent cell but differ by various mutations. In addition, the GC reaction seeds small numbers of longer-lived B lineage cells-MBC and long-lived plasma cells (LLPC) - that have been subject to this selection process. These cells, though quite rare compared to the number of GC precursor cells, confer life-long immunity and, though quiescent, are the ultimate "effector functions" spawned by the GC. Hence, the GC reaction is geared toward optimizing future immunity more than acute effector function and pathogen clearance, though under some circumstances it can participate in the latter.

\section{Key components of the GC}

GCs are composed of three main cell types: B cells, CD4 T cells and stromal cells. The GCBC have undergone a particular and distinctive type of differentiation that distinguishes them from other types of activated B cells. This includes a comprehensive alteration of gene expression, chromatin landscape and conformation, and of course protein expression ${ }^{1-3}$. A necessary and distinguishing aspect of GCBC is expression of the transcriptional repressor $\mathrm{Bcl6}^{4}$. The CD4 T cells found in the $\mathrm{GC}$ - termed follicular helper T cells-have also undergone distinctive differentiation, again mediated in large part by Bcl6 expression 5,6. These two specialized subtypes of $B$ and $T$ cell undergo extensive interactions within the GC that helps to orchestrate the evolution of diverse and high affinity B cell clones, and which also contributes to long-term $\mathrm{T}$ cell memory ${ }^{7-9}$. A potentially related subpopulation of FoxP3/Bcl6+ CD4 T cells, termed follicular regulatory $\mathrm{T}$ cells also accumulates in the GC over time; the functions of these cells are not as clear, as they may contribute to both affinity maturation and self-tolerance ${ }^{10-12}$ (see Review in this Issue).

GCs nucleate and expand within the B cell zone of lymphoid follicles, which contain a population of stromal cells called follicular dendritic cells (FDC) ${ }^{13,14}$. These cells are distinct from, but probably related to, analogous fibroblastic reticular cells found in $\mathrm{T}$ cell zones ${ }^{15}$. While the functions of FDC remain enigmatic, they are thought to provide structural and contact support for B cell follicle development as well as GC development ${ }^{16}$. Though FDC were originally reported to express both BAFF and CXCL13 ${ }^{17}$, critical factors for B cell survival and attraction, more recent data suggests that distinct fibroblastic reticular cells (not FDC) are non-redundant sources of these factors ${ }^{18}$. FDC express both complement receptors (CD21 and CD35) and Fcgr2b, both of which can trap opsonized antigen $(\mathrm{Ag})$ in the form of immune complexes (ICs) ${ }^{19-21}$. The function of $\mathrm{Ag}$ trapping is controversial (as will be discussed below), but a dominant view is that this $\mathrm{Ag}$ is critical for the development and maintenance of the $\mathrm{GC}$ as a non-redundant source of $\mathrm{Ag}$ for $\mathrm{GCBC}^{22}$. More recently a unique stromal cell was identified within a region of the GC termed the dark zone (DZ, see below), characterized by its expression of the CXCR4 ligand, CXCL12, and hence termed the CRC for CXCL12-expressing reticular cell ${ }^{23,24}$

\section{Selection in the GC}

GCBC can have four possible fates: differentiation (into MBC or PC), death, or cycling through a round of mutation and selection. The net effect is selection of higher affinity GCBC as well as development of long-lived humoral immune populations. 
Selection is the result of progressive expansion of more fit (generally thought to be "higher affinity") B cell clones and subclones-either through reduced cell death or increased cell division. Differences in fitness among B cells in a GC, with respect to affinity-based selection, must be encoded in some way by the BCR itself. Thus, the major drivers that generate the substrate for selection are somatic hypermutation of $\mathrm{V}$ regions, which occurs within the $\mathrm{GC}^{25}$ (and also outside of it ${ }^{26,27}$ ), as well as the entry into the GC of diverse, unmutated naïve $\mathrm{B}$ cells ${ }^{28,29}$. In the context of a memory response, $\mathrm{MBC}$ can also join the GC, providing additional sources of diversity as well as a higher affinity starting point for the reaction, depending upon the context (e.g. cross-reactive vs same exact antigen in the secondary response) ${ }^{30-33}$.

GCBC are in active cell cycle, with average division times estimated to be 6-8hr, likely near the theoretical limit for cell cycle length ${ }^{34-36}$. At the same time, GCBC highly express the activation induced cytidine deaminase (AID) protein, which is required to introduce various mutations into the DNA encoding immunoglobulin (Ig) V regions ${ }^{37-39}$. As a result, with each division there is an average of $0.5-1$ new mutations (mainly point mutations) per cell 40,41 . As the GC reaction reaches its peak size, the rate of cell death will approximately equal the rate of cell birth, a state that will persist for weeks to months depending upon the context. It has been estimated that at any given time between 10-30\% of GCBC cells are undergoing apoptosis, with this in part depending upon the affinity of the cells' BCR for Ag 36,42 . Thus, for long periods of time the GC reaction will churn, neither expanding nor contracting, but creating a diversity of $\mathrm{V}$ region mutants.

Cell death in the GC can in principle be due to either failure of positive selection or active negative selection of BCR mutants. Of GCBC that have failed positive selection, some mutant cells will lack a functional BCR; the most obvious mechanism for this outcome is a mutation that generates a frameshift or a stop codon, preventing protein production. However, such mutations that adversely affect fundamental structure (as opposed to mutations that adversely affect specific Ag binding because they are in or near Ag contact residues) are surprisingly common. It has been estimated that about half of all replacement mutations in the framework regions of $\mathrm{V}$ genes also will meaningfully alter relatively invariant residues and result in poorly-formed BCRs, which are subsequently selected against ${ }^{43,44}$. Since framework regions constitute $3 / 4$ of the $V$ region, and since the typical ratio of R:S mutations is $\sim 3$, this category must account for a significant fraction of all cell death in the GC. Such mutations could be considered an extreme aspect of failure of positive selection. More subtly, B cells with BCRs that had V region mutations that lowered affinity or even failed to improve affinity may fail to obtain needed positive signals (see below) to either prevent cell death or promote proliferation.

At the same time that these processes are honing GC populations in a Darwinian fashion, some GCBC exit cell cycle and differentiate into either MBC or PC. At least during the peak of the GC response, on a net basis this differentiation is of relatively small magnitude compared to the overall GC reaction ${ }^{45}$, and thus unlikely to affect $\mathrm{GC}$ cell numbers. Nonetheless, these differentiation processes are crucial; yet, their transitory nature and the relatively small number of cells that they affect at any given time, have made them difficult 
to study. Hence, the sites, stages, and signals that control MBC and PC differentiation within the GC are still in the process of being worked out, as will be discussed below.

\section{GC zonal structure}

The GC can be divided into two zones, called the "dark" and "light" zones, based on their original appearances in hematoxylin and eosin-stained histologic sections. The DZ is more densely packed with cells, the nuclei of which stain blue, hence the term "dark zone". The light zone (LZ) is populated by FDCs, whose cellular processes and cytoplasm occupy space, leading to a less packed appearance ${ }^{13,46}$. The polarization of the GC can easily be appreciated by immunohistology if the FDC are stained, which demarcates the LZ. Immunologists have been preoccupied with deciphering and specifying the unique functions of the two GC zones. In our view, it is best to describe activities and cell types that are more likely to occur in one zone vs. another, rather than to conceptualize activities as being completely specific to a particular zone. The most well-known zonal characteristic is proliferation; it was originally proposed-and is still taught-that proliferation is restricted to the DZ, where the GCBC have accordingly been termed "centroblasts" 13,46. Cells in the LZ, termed "centrocytes" were thought to be quiescent. While various histologic and cell cycle flow-based analysis does show a higher proportion of cells in the DZ are in cell cycle (e.g. in S phase), a substantial albeit lesser proportion of GCBC in the $\mathrm{LZ}$ are also in cycle $35,47,48$. Hence it is correct to state that proliferation occurs more frequently in the DZ than the $\mathrm{LZ}$ rather than solely in the $\mathrm{DZ}$. The $\mathrm{LZ}$ also contains a higher proportion of $\mathrm{T}_{\mathrm{FH}}$ cells, at a reported ratio of about 1.5:1 to 2:1; but again, there are $\mathrm{T}_{\mathrm{FH}}$ in the $\mathrm{DZ}$ as well ${ }^{49}$. Despite the less than complete segregation of cell types and activities to one zone or the other, there are clearly important functional differences between the zones of the GC.

\section{The GC cycle and its relationship to selective processes}

Perhaps the major question in the field is how does the GC process select for cells that have increased affinity for Ag. Models of mutation, affinity maturation and selection have predicted that multiple cycles of this process would be necessary in order to enrich for $\mathrm{R}$ mutations in complementarity determining regions of $\mathrm{V}$ regions to the extent seen in affinity matured B cell clones and to drive affinity-based selection. Theoretical models coupled with the notion that proliferation was restricted to the $\mathrm{DZ}$ while Ag was restricted to the $\mathrm{LZ}$ (concepts that have been more recently modified, as discussed below), suggested the notion that key events in the cycle would be zonally restricted ${ }^{50-54}$. However, it was unclear where the events that would underlie selection actually occurred and what types of inter- and intrazonal migration were taking place in the mature GC. Early in vivo imaging studies revealed multiple interesting patterns of GCBC migration, including DZ to LZ and back at relatively low but measurable levels, as well as prominent intrazonal migration in which cells turned at the border of the LZ/DZ and at the edges of the GC ${ }^{34,35,55-57}$. Contacts between GCBC and $\mathrm{T}_{\mathrm{FH}}$ were generally brief; similarly, GCBC did not often interact with FDC for long periods, although some exceptional cells could be seen dwelling adjacent to FDC. From these studies it could be concluded that there are flexible paths for GCBC and multiple modes of cell-cell interaction; however, there was not sufficient data in terms of quantity or duration of cell interactions to make firm conclusions or to build convincing models. 
A major breakthrough was the use of photoactivatible GFP to label cells in a region at a given time, followed by tracking of such labeled cells into different zones at various subsequent times ${ }^{58}$. This, coupled with experimentally delivering of $\mathrm{T}$ cell Ag to all GCBC, thus conferring the ability to recruit $\mathrm{T}$ cell help to GCBC en masse, allowed a more precise understanding of events and movements associated with positive selection. In this landmark study, Victora et al found that initial encounter with $\mathrm{T}$ cell help led first to GC retention in the LZ for up to $12 \mathrm{hrs,} \mathrm{followed} \mathrm{by} \mathrm{GCBC} \mathrm{migration} \mathrm{into} \mathrm{the} \mathrm{DZ.} \mathrm{Under} \mathrm{the} \mathrm{conditions}$ studied, which most likely involved supraphysiologic T cell-derived signals, these GCBC remained in the DZ for several days, where they proliferated. This population of GCBC then emerged from the $\mathrm{DZ}$ and some of them migrated to the LZ, while others most likely died. These observations were most compatible with a model in which productive $T$ cell encounter in the LZ triggers a shift in gene expression (specifically chemokine receptor expression), that leads to migration towards the DZ. In the DZ proliferation for one to a few cell cycles ensues, along with rounds of somatic $\mathrm{V}$ region mutation, followed by quiescence and return to the LZ. In the LZ, affinity of newly mutated receptors is again tested as a function of ability to capture and present Ag to T cells.

\section{$\mathrm{Ag}$ in the GC}

While these studies provided a basic outline of how GCBC traffic and respond to T cell help, they did not elucidate how GCBC received and processed Ag-dependent signals that would lead to positive selection of higher affinity GCBC. The first question to be addressed in how affinity is tested asks where $\mathrm{Ag}$ comes from and in what forms is it encountered by B cells in the GC. The observation that Ag can be seen deposited on FDC of immune animals 14,59-61 has sparked a debate about how GCBC encounter Ag. FDC do not possess universal receptors for all type of $\mathrm{Ag}$, but rather can bind to immune complexes that consist of $\mathrm{Ag}$ that has already elicited an immune response or at the least has been recognized by the immune system, i.e. has been "opsonized" 62-64. There are two receptors that mediate opsonized Ag capture by FDC: CR1/2 (CD21/35) and Fcgr2b 20,65-68. The ligands for these receptors generally depend on Ig binding to Ag; the only exception would be the relatively few Ags that naturally activate the alternative pathway of complement and can fix $\mathrm{C} 3$ and $\mathrm{C} 4$ fragments to themselves in the absence of any Ig.

It is well-known that B cells, unlike MHC-restricted T cells, respond to soluble Ag both in vitro and in vivo. Indeed, it is well-accepted that primary B cell responses initiate in response to soluble antigens. While some studies have argued that only relatively smaller Ags can rapidly transit "conduits" that lead from capsular lymphatics to the center of B cell follicles ${ }^{69,70}$, multiple other studies have indicated that Ags that are at least the size of immunoglobulins can reach follicular B cells and bind their BCRs within a matter of a few hours post-injection, if not more quickly ${ }^{71-74}$. Our recent experiment, in which we injected soluble anti-IgM into mice harboring active GCs, demonstrated a biological effect of induction of c-Myc protein expression, in just four hours, indicating a very rapid delivery of the initial signal ${ }^{73}$. Hence, it seems that soluble Ag can indeed reach GCBC and ligate their BCR effectively. 
Nonetheless, based largely on observational studies of the presence of Ag in immune animals as well as in vivo imaging in which B cells can be seen capturing Ag that had been seeded on FDC ${ }^{69,75-78}$, a standard thinking has emerged that GCBC normally do or even must obtain their Ag from FDC and not from the "soluble" milieu ${ }^{79,80}$. To test this idea, some years ago, we created mice that had B cells carrying a B1-8 VDJ transgene linked to a mutant IgM constant region that could only express membrane, but not secreted Ig. Together with a $\lambda 1$ light chain, the IgH chain encodes anti-nitrophenyl (NP) specificity and the mice mount responses to NP; however, we found that the mice can respond to diverse Ags by combining this $\mathrm{Vh}$ transgene with other $\mathrm{L}$ chains ${ }^{81}$. Whether immunized with NP-carrier or carrier alone, these animals made vigorous, and in fact supra-normal, GC responses. Yet, lacking soluble $\mathrm{Ab}$, they had no means to deposit Ag on FDC via either of the two Agcapture receptors on FDC (and we were able to show at least a 1,000 fold decrement of $\mathrm{Ag}$ deposition to undetectably low levels). In addition, Manser and colleagues found that amplified IC deposition on FDCs seen in mice that lacked the common FcR gamma chain (and hence did not trap ICs on other cell types) did not result in an enhanced GC response 82. Furthermore, mice lacking Fcgr2b did not have reduced GC magnitude or kinetics, although IgG IC deposition on FDC would have been reduced in such mice ${ }^{83}$. Robust GC reactions can also be elicited simply by the transfer of $\mathrm{B}$ cells that express a retroviral superantigen in a system that lacked detectable FDC and which in any case would have been unlikely to permit Ag-capture by FDC ${ }^{84}$. Thus, while under some circumstances GCBC likely can productively encounter Ag on FDC, at least in the case of soluble Ags, such encounter is not necessary to promote normal or even exaggerated GC responses.

$\mathrm{CR} 1 / 2$ ligation on FDC is also important for the GC reaction, as shown by bone marrow chimera experiments ${ }^{85,86}$, but this continues to be the case even when there is no $\mathrm{Ab}$ available to fix complement ${ }^{87}$. To resolve this apparent paradox, we used a genetic BCR engineering approach to create mice that could neither secrete Ig nor fix $C^{\prime}$ at the membrane surface due to a mutation in the BCR CH2 domain ${ }^{87,88}$. These B cells, unlike WT B cells, could not fix C' to their own surface and did not facilitate $\mathrm{GC}$ responses. From these experiments we concluded that CR1/2 ligation on FDC likely provides positive signals to these cells and that $\mathrm{B}$ cells can fix $\mathrm{C} 3 / \mathrm{C} 4$ fragments to their own surface upon BCR ligation (as also concluded by others ${ }^{89}$ ) and that these ligands can provide signals to both B cells and FDCs. In any case, we could not find evidence of positive non-redundant roles for Ag deposited on FDC.

These results directly challenged the current dogma that Ag needs to be presented to GCBC on the surface of FDC. While several reviews did acknowledge these results ${ }^{22,80,90}$, it was not widely credited, with nearly all reviews and diagrams depicting the recognition of $\mathrm{Ag}$ by GCBC on FDC surfaces, rather than as soluble Ag ${ }^{91,92}$. Most recently we retested this issue in a novel system. We immunized a different strain of mice that also expressed only surface BCR but lacked secreted Ig; in this strain, BCRs assembled normally in the endogenous locus. Similar to our previous result, we obtained massive GC responses, despite the fact that these mice could not opsonize Ag and therefore could not deposit it on FDC ${ }^{73}$. In fact, analysis of c-Myc expression in the GCBC of these animals (see below) suggested that they were achieving an abnormally high degree of BCR signaling, despite the lack of $\mathrm{Ag}$ opsonization and deposition. This discussion challenges the field to reconsider its still- 
current dogma, and to evaluate the hard evidence that supports the idea that Ag only reaches BCRs on GCBC in the LZ that interact with FDC.

If $\mathrm{Ag}$ on $\mathrm{FDC}$ is not required for $\mathrm{GC}$ development and maintenance, then what is the purpose of Ab-dependent Ag-deposition on FDC? We have suggested ${ }^{93}$ that such Ag could be suppressive, by providing a source of ligand for Fcgr2b that is expressed on GCBC. Normal GCBC upregulate Fcgr2b, while GCBC from autoimmune-prone mice that tend to make larger GC reactions do not do this, suggesting that Fcgr2b may play an important inhibitory role on GCBC ${ }^{94}$. Further, Tiller et al. found that self-reactive GCBC developed selectively in mice lacking Fcrg2b, again consistent with the notion that Ag trapped by this receptor on FDC plays a tolerizing role ${ }^{95}$. It could even be argued that $\mathrm{Ag}$ on FDC is unlikely to be readily accessible to GCBC BCRs, as the available epitopes will likely be bound by pre-existing Ab that served to opsonize the Ag. Such interactions that lead to IC formation tend to be highly stable and not easily reversible within the context of a complex $\mathrm{Ag}-\mathrm{Ab}$ lattice. In line with this idea, GCs in both strains of mice that lacked secreted $\mathrm{Ab}$ (and thus lacked ICs on FDC) were unusually large and in the most recent publication it was shown that a high fraction of the GCBC had evidence of a recent positive BCR signal ${ }^{73,81}$. This would be in keeping with more, rather than less, Ag signaling in the absence of FDC Ag capture. In this vein, an additional and non-exclusive function of FDC Ag-capture could be to reduce Ag concentration, thus making it more limiting and thereby driving affinity maturation through more intense selection.

\section{How does Ag signal to the GCBC?}

Since the GC is thought to be continually Ag-driven, and affinity maturation by definition is driven by Ag, signals that depend on the interaction between Ag and the GCBC are central to understanding how the GC functions. Ag could affect GCBC by two major mechanisms: it can signal via the BCR, or it could be captured via the BCR and peptides derived from it presented on MHCII, garnering various signals from cognate $\mathrm{T}$ cells. These latter signals could include CD40L, IL-21 and other cytokines, adhesion molecule interactions, and other less-well defined contact-dependent costimulatory interactions.

\section{BCR signals}

With the hypothesis that affinity maturation in the GC must relate to differences in how the signals of high and low affinity BCR ligation are either generated or interpreted, we set out to define BCR signaling in GCBC and how it compared to that in naïve B cells (NBC). Using a combination of flow cytometry and western blotting, we were surprised to find that BCR signals in the GC were markedly attenuated; reduced signaling could be tracked back as far as the phosphorylation of CD79, the BCR signal transducing components 96 .

Biochemical and inhibitor data pointed to increased phosphatase activity as a major reason for reduction in GCBC BCR signal transduction. However, we did not identify specific phosphatases, although we presented some evidence that both SHIP-1 and SHP-1 may be activated in GCBC.

Subsequently, similar data in different systems were reported by others. He et al. found reduced BCR proximal signaling activity in both $\mathrm{IgG} 1$ and $\mathrm{IgE}$ expressing GCBC in mice ${ }^{97}$. 
Using Nur77-GFP Tg mice, which carry a reporter of BCR (and to a lesser extent CD40) signaling, Zikherman and colleagues also found evidence of less spontaneous and inducible GCBC BCR signaling in the form of reduced GFP expression ${ }^{98}$. Nowosad et al. found reduced proximal BCR signal transduction in response to soluble BCR ligands, but using image analysis they concluded that GCBC had intact proximal BCR signals when presented with highly crosslinking ligand contained on membranes. These data suggest that, at least to some extent, the relative block in proximal BCR signal transduction in GCBC could be overcome with very strong ligation (and/or specific qualitative aspects of ligation such as inability to internalize the ligand). Nonetheless, even very strong ligation resulted in no detectable NFkB nuclear translocation in GCBC ${ }^{99}$.

\section{T cell-mediated signals}

The finding that BCR signaling was relatively desensitized in GCBC suggested that positive selection could largely if not entirely be driven by $\mathrm{T}$ cell signals that would be delivered preferentially to those GCBC that succeeded in capturing and presenting peptides from $\mathrm{Ag}$ most efficiently, which in turn would be a function of BCR affinity ${ }^{58,100}$. Indeed, MHCII expression on $\mathrm{B}$ cells is required for GC development and maintenance ${ }^{101}$.

One prominent T cell signal is CD40L; it has long been known that blocking CD40L:CD40 interactions leads to acute dissolution of the GC reaction ${ }^{102}$. A second important signal is IL-21. In the absence of IL-21R on B cells, GCs form but they are not well-sustained once they reach peak ${ }^{103,104}$. IL-4 can also contribute to GC development and growth, particularly in synergy with IL-21 104,105.

The interactions between $\mathrm{GCBC}$ and $\mathrm{T}_{\mathrm{FH}}$ are mutual and the nature of these mutual interactions could determine selection. GCBC express CD80 and CD86, with the latter being particularly critical for sustaining the GC reaction, presumably via signals through CD28. Perhaps more interestingly, Qi and colleagues have provided in vivo imaging data supporting a model in which the quality of the signal received by GCBC from T cells leads to commensurate upregulation of ICOSL on the GCBC, due to increased receipt of CD40 signals from the $\mathrm{T}_{\mathrm{FH}}$, resulting in an affinity-selecting positive feedback loop. The more productive signals from this positive feedback can be visualized as an "entangled" interaction between GCBC and $\mathrm{T}_{\mathrm{FH}}$ which is both more prolonged and complex, resulting in Ca signaling ${ }^{100}$.

Integrins, which are known to control the quality and duration of cell-cell interactions, are also important in the GC reaction. Integrins can affect GCBC-FDC interactions ${ }^{16}$ as well as GCBC- $\mathrm{T}_{\mathrm{FH}}$ interactions ${ }^{106}$. Although genetic deletion of key integrins does reduce GC quality and affect affinity and diversity 16,106, whether these integrins are modulated naturally in an affinity-dependent way has not been demonstrated. Thus, it is unclear if, under normal circumstances, integrins selectively influence affinity maturation.

\section{Signal integration and interpretation for positive selection}

Although the surface receptors on GCBC that could transduce positive selection-such as $\mathrm{BCR}, \mathrm{CD} 40$ and cytokine receptors—have been known for many years, their identification 
did not explain how signals from them, either singly or in combination, would be interpreted by GCBC to lead to positive selection. Elucidation of how these receptors signal in concert to promote selection is key to understanding how positive selection occurs (i.e., increased proliferation and/or decreased cell death), as well as how higher affinity cells are favored in this process.

\section{c-Myc upregulation as a signal of positive selection}

A key insight into how positive selection is orchestrated was the understanding that c-Myc induction was likely linked to, and a sign of, successful positive selection ${ }^{107}$. While c-Myc is only expressed by a small minority of GCBC, it was shown that lack of c-Myc prevented GC formation while inducible deletion or antagonism ablated existing GCs 107,108 . Moreover, c-Myc+ cells were mainly in the LZ and acute induction of strong T cell help turned on c-Myc transcription in LZ cells, though the fraction of responding cells was not ascertained in this experiment ${ }^{107,108}$. Interestingly, GCBC that expressed a c-Myc reporter had an enrichment of affinity-enhancing somatic mutations in their $\mathrm{V}$ regions, linking c-Myc expression with fitness in the GC ${ }^{107}$. In subsequent work, Ersching et al. ${ }^{109}$ further connected positive selection-dependent on CD40 - to mTORC1 signaling that led to increased cell size, generation of p-S6, and migration to the DZ; somewhat surprisingly mTORC1 signaling was not required for proliferation, though.

\section{Signal rewiring in the $\mathrm{GC}$ that tunes for positive selection}

The work of Victora, using the experimental technique of directing strong $\mathrm{T}$ cell help to GCBC $58,107,109$, as well as other studies ${ }^{100,110}$ clearly established a key role for T cellderived signals in mediating GCBC positive selection. In addition, the evidence described above suggested that BCR signals may not contribute to positive selection per se. What remained unaddressed was how GCBC interpret T cell-derived signals, in particular CD40L and IL-21.

To address this, we first looked at whether CD40 signals were reprogrammed in GCBC. Indeed, we found that in GCBC, compared to NBC, PI3K signals were markedly attenuated following CD40 ligation, whereas NFKB signals were largely intact ${ }^{73}$. This finding created a conundrum, in that PI3K signals are required to activate AKT, which in turn is needed to phosphorylate and inactivate FOXO1 ${ }^{111-113}$. As neither BCR nor CD40 signals seemed to engage the PI3K pathway, we could not understand how FOXO1 could be regulated in the GC. Two other groups had already shown key roles for PI3K signals and FOXO1 in maintaining the DZ; when FOXO1 is deleted or when PI3K signaling is constitutively turned on (which leads to phosphorylation and nuclear exit of FOXO1), the DZ collapses 113,114 . Consistent with this, FOXO1 was shown to be required for DZ maintenance and in the T cell-induced LZ to DZ transition ${ }^{115}$. Notably, in other cell types, FOXO1 is a wellcharacterized suppressor of c-Myc expression ${ }^{116}$, which suggested a potential link between FOXO1 inactivation and c-Myc upregulation in positive selection.

The realization that we had not identified a path from either BCR or CD40 to PI3K/AKTdependent FOXO1 phosphorylation caused us to reexamine BCR signaling in the GC, using 
a more sensitive phosphoflow protocol that we had developed. Indeed, we were able to detect a small but significant transient pulse of p-Syk immediately following BCR ligation of GCBC; it was substantially smaller and decayed more rapidly than that generated in NBC 73. Most importantly, by directly examining FOXO1 we found strikingly efficient and rapid generation of p-FOXO1 following BCR ligation in GCBC. As expected, this led to nuclear exit of FOXO1 within a few minutes of BCR ligation in both GCBC and NBC. These data are consistent with the results of Mueller et al. showing Nur77-dependent GFP expression in some $\mathrm{LZ} \mathrm{GCBC}{ }^{98}$. Interestingly, other signals downstream of AKT and the mTORC1 complex, such as generation of p-S6, remained highly attenuated in GCBC vs NBC ${ }^{73}$.

Since c-Myc transcription is typically repressed by FOXO1 116 yet induced by NFKB 117,118 , and we found that BCR - but not CD40 - inactivates FOXO1 whereas CD40 - but not BCR - induces NFKB, we hypothesized that only via signals through both receptors could c-Myc be induced. Indeed, experiments showed this to be the case both in vitro and in vivo in $\mathrm{GCBC}$, while either BCR or CD40 signals were sufficient to induce c-Myc expression in NBC. Through these studies we could link two Ag-driven signals to the key positive selection checkpoint of c-Myc upregulation. Notably, Ersching et al. ${ }^{109}$ have connected positive selection to activation of $\mathrm{m}$-TORC1 and subsequent generation of p-S6 (a standard readout), and consistent with this we also observed late induction of p-S6 upon delivery of a dual BCR/CD40 signal. The signals, when delivered in vivo, caused modulation of GC zonal surface marker expression and of cell location as predicted by the overall model. We proposed that by requiring both productive $\mathrm{T}$ cell interactions (via CD40 ligation) and direct Ag signals, GCBC signal wiring is optimized to select for higher affinity 73 .

We have discussed above how a higher affinity BCR could determine an increased likelihood of getting adequate T cell-derived signals, thereby promoting T-B "entanglement" to prolong and enhance the signal to the $\mathrm{T}$ cell, resulting in a positive feedback loop. Indeed, theoretical considerations suggest that such positive feedback is necessary to enhance affinity selection 119. While the affinity-dependence of the strength or quality of this signal for the B cell has not been investigated directly, it is reasonable to think that higher affinity cells will get a stronger signal with possibly more induction of c-Myc as a consequence. Both antibody staining and a c-Myc-GFP reporter have revealed a relatively broad distribution of c-Myc levels in the GCBC that do express the protein, consistent with a diversity in strength of "positive selection" encounters in vivo ${ }^{107,108}$. This area warrants further experimentation.

Cells that are positively selected also appear to avoid apoptosis, suggesting that the signaling mechanisms should induce anti-apoptotic mechanisms ${ }^{36,42}$. Indeed, older literature connects a combination of BCR and CD40 signals with induction of bcl-2 family members, though there was disagreement as to which bcl-2 family member was critical ${ }^{120-122}$. Exactly how expression of anti-apoptotic proteins is controlled by key signals to GCBC is not clear.

There are also observations that link positive selection with an increased probability to enter cell cycle and/or to continue cell cycle. While mTORC1 induction led to an increase in GCBC cell size and an anabolic state, it was not strictly required for actual cell cycle 
progression ${ }^{109}$. Still, positive selection seemed at the least to prepare cells and enable cell cycling. c-Myc expression is linked with entry into the cell cycle and in non-GCBC the extent of induction of c-Myc is highly correlated with the number of cell divisions that a cell can subsequently undergo, with division stopping as c-Myc levels decay ${ }^{123}$. It is thus tempting to suggest that in GCBC the extent of c-Myc induction is proportional in an analog way to the strength of combined T cell-derived (e.g. CD40) and BCR-derived signals that in turn are proportional to the potential for multiple rounds of division after the selection step. Commensurate with this notion are data from Gitlin et al. linking the extent of positive selection via $\mathrm{T}$ cell-derived signals with a shortened S-phase and more cell division in the DZ ${ }^{48,124}$, though how S-phase duration might be controlled by c-Myc remains to be determined. This is unlikely to be the only mechanism regulating positive selection, because too many divisions without selection will not allow for R/S enrichment and would result in many cells with loss of affinity subsequent to having had an affinity-improving mutation $54,125,126$.

To reconcile and unify these observations, we present a "hybrid model" (Figure 1) in which BCR signals alone promotes initial migration of DZ GCBC and "licenses" the GCBC to remain in the $\mathrm{LZ}^{73}$. We propose that $\mathrm{BCR}$ signals also induce or sustains anti-apoptotic factors. This in turn increases the likelihood of the partiall-selected GCBC to obtain a complementary signal via T cells (via CD40 and cytokine signaling). Consistent with this element of our model, Mayer et al showed that BCR signaling in GCBC, as revealed by Nur77-GFP expression, was more frequent than Myc expression; Nur77-GFP expressing cells were partly protected from apoptosis while Myc expressing cells were more fully protected ${ }^{36}$. Also consistent with a role for BCR signals providing an anti-apoptotic effect is the slow loss of GCBC (about two-fold in 2-3 days) after inducible Syk deletion in GCBC, which had abrogated BCR signals ${ }^{73}$. Successful T cell-mediated signal delivery in the LZexemplified by CD40 ligation in our work ${ }^{73}$ or DEC205 Ab-mediated recruitment of comprehensive $\mathrm{T}_{\mathrm{FH}}$ help in the work of Victora et al. ${ }^{58}$ — would then lead to completion of a positive selection cycle, with induction of an anabolic state along with DZ transition, followed by proliferation in proportion to the amount of c-Myc induced.

\section{Cell intrinsic vs competitive selection}

Affinity selection can be considered either cell-intrinsic or cell-extrinsic; in vivo there could be a combination of both types of selection. Affinity intrinsic selection would occur when a cell with lower affinity responds less optimally compared to a higher affinity cell, regardless of whether there is competition from other clonotypes or even when Ag is not limiting; such responses would be hard-wired differential read-outs of affinity. That cell-intrinsic selection exists is well-known and has been the topic of much of this review to this point. Cellextrinsic forces are implicated when the response of a given cell is conditioned by the presence of more highly fit competitors. Cell-extrinsic forces could be passive, for example by causing Ag clearance that in turn engages cell-intrinsic selection against cells with lower affinity. Alternatively, such forces might be active, for example by altering the milieu or even secreting inhibitory substances that tend to suppress less fit cells. 
In an early investigation of this issue, we demonstrated in 2002 that very low affinity antiNP B cells that normally would never be found in a polyclonal GC reaction do in fact enter the GC when rendered the dominant clonotype by virtue of a BCR transgene ${ }^{127}$. These data suggested that in the absence of competition this low affinity clonotype could perform better, evidence for cell-extrinsic forces in the GC response and/or the events leading up to it. However, these responses were much smaller than those elicited in mice with a comparable BCR transgene that encoded higher affinity for the same haptenic Ag (a germline VDJ that would be common in the primary response), providing evidence for cell-intrinsic lower fitness even in the absence of competition. We subsequently found that even very small numbers of medium affinity B cells would suppress vast excesses of low affinity B cells, preventing them from ever forming a GC response, which provides evidence of cell-extrinsic competition (unpublished observations). Nussenzweig and colleagues set up a system similar to ours, by inserting high affinity (higher than germline) and low affinity encoding VDJs into the endogenous IgH locus, where the constructs could undergo mutation (whereas in our case the non-mutating ectopic Tg served to fix the low or medium affinity in place). Somewhat in contrast to our results, they found that in the absence of competition both low and high affinity BCRs performed equally well, whereas they directly demonstrated the superiority of the high affinity cells when placed in competition ${ }^{30}$. In retrospect, the failure to observe cell-intrinsic defects may have been due to the ability of the site-directed BCR transgene to undergo affinity-improving mutations that compensated for its initial low affinity.

It has also been suggested that $\mathrm{Ab}$-mediated clearance of $\mathrm{Ag}$ can be a driver of competition, and this would seem undoubtedly to be true ${ }^{128}$. The large GCs observed in mice lacking secreted $\mathrm{Ab}{ }^{73,81}$ could in part result from lack of overall $\mathrm{Ab}$-mediated Ag clearance.

However, whether Ab can mediate inter- or intra-clonal competition within individual GCs seems questionable, as GCBC do not secrete Ig; the Ig that is made early comes mainly if not exclusively from EF plasmablasts, that are generally of very low affinity and thus not likely to promote much competition with higher affinity GCBC ${ }^{129,130}$. In any case, it seems unlikely that $\mathrm{Ab}$ per se would mediate intra-GC competition.

Another possible vector for intra-GC competition could be physical and direct competition for $\mathrm{T}_{\mathrm{FH}}$ interactions. This seems plausible, as $\mathrm{T}_{\mathrm{FH}}$ are limiting in the $\mathrm{GC}^{6,49}$. However, the great majority of $\mathrm{T}_{\mathrm{FH}}$ interactions with GCBC seem to be quite short $34,100,131$, seemingly limiting the potential of a high affinity $\mathrm{GCBC}$ to sequester a $\mathrm{T}_{\mathrm{FH}}$ from a lower affinity cell.

\section{What is the fate of cells that do not get positive selection signals?}

This is a difficult question to answer directly by experiment, compared to tracking the fates of cells that in fact $d o$ (via experimental means) get such signals. Differentiation is one option, as we will discuss below. Death vs failure to proliferate are the other two potential outcomes, and these are not mutually exclusive. Using mice that have either fixed higher or lower affinity for the same hapten, NP, we measured both proliferation and death rates among Ag-specific GCBC. Somewhat surprisingly, GCBC had roughly similar rates of proliferation, regardless of affinity, while the fraction of GCBC undergoing cell death, as measured by the viable apoptosis dye zVAD-fmk-FITC, was $\sim 3$ times greater in the lower 
affinity cells ${ }^{42}$. This led us to conclude that differential protection from cell death was a major mechanism of selection. We presented a detailed mathematical model to account for GC turnover in the normal and low affinity situation. However, it must be cautioned that this was in a non-competitive situation and may have only measured one dimension of selection.

Mayer et al. ${ }^{36}$ recently revisited the issue that we had addressed, using both an Ab to activated Caspase 3 as well as a novel reporter mouse. They found similar, or perhaps slightly lower rates of apoptosis, as our prior study ${ }^{42}$, as well as similar rates of labeling with a thymidine analog to measure division. They also confirmed earlier work ${ }^{132}$ showing that AID-negative GCBC had somewhat lower but still substantial rates of apoptosis (about 65\% of WT overall in Peyer's patches). Importantly, they found that apoptosis was more frequent in phenotypically DZ GCBC and that this apoptosis was largely AID-dependent. Sequencing of $\mathrm{V}$ regions from apoptotic cells demonstrated that a large fraction - though far from allcontained stop codons or out-of-frame nucleotide insertions. Hence, they concluded that the DZ was the site of death of cells that had recently received inactivating mutations via AID. Though not directly analyzed, it seems likely that other dying cells in the DZ had missense mutations in relatively invariant residues of $\mathrm{V}$ region framework regions; it is well-known that these are also selected against resulting in an overall loss of about $50 \%$ of $\mathrm{R}$ mutations in these regions, and a replacement:silent mutation ratio of about 1.5. Indeed, Mayer et al. nicely showed that many of the Ig that they reconstituted from single apoptotic DZ cells were expressed, yet unstable, consistent with the presence of mutations in framework regions that disturbed Ig $\mathrm{V}$ region fundamental structure. Their work also showed that only LZ GCBC that reported c-Myc expression, and not those reporting only BCR signaling (as indicated by a Nur77-GFP reporter), were protected from apoptosis. This is consistent with apoptosis also being a fate of cells that failed positive selection, again as suggested by other reports and by mathematical models 42,54 .

\section{The GC is an imperfect selection engine and is also designed to generate diversity}

An issue less-often discussed, but of great biological and conceptual significance, is the inherent variability of the GC response. This can be looked at in terms of the variant results across different GCs responding in the same animal as well as within individual GCs $25,28,29,40,125,133$. While affinity maturation is often discussed as the sole purpose of the GC, in fact generation of inter- and intra-clonal diversity also occurs ${ }^{40}$ and is likely to be quite important, particularly for defense against recurrent or chronic pathogens that themselves undergo high rates of variation ${ }^{134-136}$. Elegant work by Tas et al. has shown directly that individual GC are seeded by likely hundreds of cells, are only sometimes oligoclonal, and do not all contain high affinity clones ${ }^{29}$. This was a result predicted by modeling approaches, which demonstrated how often clones tend to fail under the weight of somatic hypermutation and how pathways to high affinity are sometimes quite unlikely, leading to affinity maturation only some of the time even under optimal conditions ${ }^{54,125}$. Similarly, Kuraoka et al. demonstrated, using complex Ags that are more physiologic than haptens, that concurrent with affinity maturation is wide variation in affinity of GCBC, as well as a large fraction of GCBC that do not demonstrably bind Ag to which they were likely originally 
elicited ${ }^{137}$. These results suggest that some low affinity mutants can survive in GC for extended periods.

While we tend to conceptualize GC in a monolithic way, with LZ-specific or DZ-specific only functions, an absolute need for Ag to be harvested from FDC, etc., in fact there is tremendous variation and flexibility in GC function and thus likely multiple pathways towards different outcomes. This more flexible view tends to mesh with the notion that GCs are designed to create diverse outcomes, of which affinity maturation is just one, and which includes the generation of a diverse set of Ag-binding clones that can anticipate future antigenic variation by pathogens as well as create different types of long-lived effectors.

\section{Signals for differentiation in the GC}

The GC is conventionally considered the exclusive source of MBC and LLPC. In reality, substantial work in the last 10 years has revealed that a remarkable fraction of the MBC pool formed in response to immunization in mice is actually independent of the GC, is often not isotype-switched, and carries relatively few V region mutations ${ }^{45,138-141}$. Nonetheless, many $\mathrm{MBC}$ are indeed formed in the GC and most evidence indicates that the vast majority, if not all, LLPC are also formed in the GC, at later time points ${ }^{45}$. This raises the question of what signals and events promote GCBC differentiation rather than continuation of GCBC phenotype, positive selection, and/or death. Beyond that, in a GCBC that is differentiating to a long-lived progeny cell, what promotes an MBC vs a LLPC fate?

Using an in vivo pulse-chase BrdU labeling approach, combined with $\mathrm{V}$ region sequencing and anti-CD40L treatment at defined time points, we recently showed that $\mathrm{MBC}$ emerge before LLPC, with not much overlap between the two populations ${ }^{45}$. These conclusions were subsequently confirmed by similar pulse tamoxifen treatment using a tamoxifenresponsive Cre in GCBC ${ }^{142}$. In addition, MBC that express PD-L2 or both PD-L2 and $\mathrm{CD} 80$, emerge at progressively later time points. This suggested that GCs evolve over time from a state early-on that is more favorable to $\mathrm{MBC}$ formation to a state that is more favorable to LLPC differentiation. However, no specific molecular mechanism was revealed.

In the past two years a few salient reports have emerged that either identify key transcription factors that are regulated in the $\mathrm{GC}$ to $\mathrm{MBC}$ transition or demonstrate cell surface phenotypes that mark precursors of MBC within the GC. Kometani et al. demonstrated that Bach2 expression in the GC predisposed GCBC to MBC differentiation and that this was correlated with lower affinity of the BCR ${ }^{143}$. They suggest that lack of $\mathrm{T}$ cell signals, as a result of lower BCR affinity, may promote MBC differentiation.

Qi and colleagues reported that IL9R ${ }^{+}$GCBC were precursors for MBC and that IL-9 helped drive this process ${ }^{144}$, though this has been challenged by subsequent studies ${ }^{145}$. Laidlaw et al. described a population of EphB1+ GCBC that have downregulated Bc16, S1PR2 and upregulated CD38 that they term GC Premem cells, as likely MBC precursors ${ }^{146}$. These cells were found mostly at the periphery of the LZ. Suan et al. identified a potentially similar population of $\mathrm{CCR}^{+}$cells in the $\mathrm{LZ}$ that were relatively quiescent, were enriched for low affinity (but had some higher affinity cells), and had characteristics of MBC ${ }^{147}$. Taken 
together these data suggest that MBC arise from "non-selected" cells in the LZ and-either due to cause or effect - are of lower affinity. This is consistent with the data that MBC arise earlier in the GC and have fewer V region mutations, both of which are associated with lower affinity 45,142 . Nonetheless, most non-selected cells are expected to die, rather than differentiate, given the relatively small numbers of $\mathrm{MBC}$ created in a response 138,141,148-151; the signals that distinguish those cells undergoing MBC transition vs death remain undefined, again in a cause and effect sense.

Initial searches for PC-precursors among GCBC focused on finding Blimp1+ cells, but failed to identify such cells convincingly, whereas Blimp1+ PC-precursors could be found in peripheral blood ${ }^{152-154}$. Recently, Krautler et al. ${ }^{155}$ reported on a small population of Blimp1+ cells ( $~ 0.25 \%$ of GCBC) that also were CD38 ${ }^{\text {lo }}$, like GCBC, and expressed genes upregulated in PCs. These cells tended to have higher affinity for Ag, and were denoted as putative PC precursors, although no precursor-product experiment was performed to test this idea. Although an earlier report claimed that higher affinity GCBC were selected into the PC compartment, in a directed rather than correlative fashion 156,157 , later work on an analogous interpretation of extrafollicular plasmablast selection revised that conclusion to indicate that higher affinity cells were selected for more expansion, rather than for differentiation ${ }^{158}$. It seems likely that the same applies for the GC and that the association between higher affinity in the $\mathrm{GC}$ and the $\mathrm{PC}$ compartment is likely a correlation that results from PC differentiating later in the GC reaction, when the average GCBC does have higher affinity 45. To be clear, this does not rule out that affinity does play some part in directing PC differentiation, but this has not been demonstrated in a cause-effect fashion.

The GC appears to produce two waves of AFCs, the first of which includes short-lived plasmablasts that seed the spleen and may also seed the BM but not survive there for long periods ${ }^{159}$. The second wave, as noted, occurs much later, and is the source of long-lived non-cycling PC that reside mainly in the $\mathrm{BM}^{45}$. It is possible and even likely that the signals that produce these two waves could be different, even if there are some similarities in the precursor and product cells. Recently, Zhang et al. proposed that an early wave of GCBC may differentiate and exit as plasmablasts near the GC T cell zone border at the base of the DZ ${ }^{159}$. Direct lineage tracing and quantitative observation of differentiation and exit at this site would bolster this intriguing new model.

Ise et al. ${ }^{160}$ recently identified a population of $\mathrm{Bcl} 66^{\mathrm{lo}} / \mathrm{IRF} 4{ }^{\text {hi }} \mathrm{GCBC}$ with a $\mathrm{LZ}$ phenotype, that have characteristics in common with new emigrant PB from the GC; they suggested that this population was induced by $\mathrm{T}$ cell help signals, particularly via CD40. However, this work also did not directly demonstrate a precursor-product relationship between these LZ GCBC and plasmablasts generated from the GC, and so does not provide conclusive proof of the model. It is additionally hard to reconcile the models of Zhang et al. (with plasmablasts differentiating at the base of the DZ) with Ise et al. (with plasmablasts differentiating from IRF4 ${ }^{\text {hi }}$ cells in the LZ). Clearly, while progress is being made, more work is needed to decipher the signals that lead to either MBC or PC differentiation of GCBC and to better verify the identity of any putative precursors of either population. 


\section{The nature and importance of negative selection in the GC}

One of the major conundrums of the $\mathrm{GC}$ reaction is how $\mathrm{GCBC}$ can simultaneously be selected for stronger binding to foreign Ag while at the same time selecting against anti-self B cells. This arises because somatic mutations will inevitably cause autoreactivity, either de novo or via augmentation of preexisting weak autoreactivity $43,161-163$. Indeed, there is evidence that the GCBC compartment does contain autoreactivity and that some of these cells differentiate into the MBC compartment ${ }^{95,164}$. Hence, selection against autoreactive mutant BCRs in the GC is likely to be inefficient, at best.

We previously suggested a model that would explain the relative desensitization of BCR signals as a means to discriminate self and non-self in the $\mathrm{GC}^{96}$ : positive selection in the $\mathrm{GC}$ begins only after a substantial effector response that generates $\mathrm{Ab}$ has occurred. Thus, available $\mathrm{Ag}$ is likely to be limiting in the $\mathrm{GC}$, particularly when mutation frequencies begin to rise (and hence the likelihood of autoreactivity also rises), near the end of the second week of the immune response. Whereas, "self" is likely to be highly prevalent and highly cross-linking, being expressed on multiple cell surfaces and without pre-existing Ab. BCR desensitization in the GC allows for a certain quality of BCR signal in response to foreign $\mathrm{Ag}$ (e.g. that inactivates Foxo1) to be transduced, without causing a substantial NF-kB (or other) signal ${ }^{73}$. However, a very strong signal may override negative regulatory mechanisms, such as high phosphatase activity, in GCBC and lead to more complete BCR signaling. We proposed that this would be interpreted as a negative signal and potentially lead to GCBC apoptosis, much as such signals do in developing immature B cells. While this might not eliminate all anti-self B cells, it would censor high affinity B cells that bind to cell surfaces or abundant self-Ag, such as debris from dying cells that is formed by the constant death of GCBC.

In support of this concept are a series of experiments performed in several labs in the mid-1990s in which various forms of $\mathrm{Ag}$ were injected at very high concentration into mice with ongoing GC reactions ${ }^{165-167}$. In each case these injections caused rapid apoptosis of GCBC, mostly in the LZ, which was only partly rescued by bcl-2 overexpression. While in some cases this was interpreted as due to interaction with monomeric $\mathrm{Ag}$, when tested directly polyvalent or higher affinity Ag was clearly more potent ${ }^{168}$. In all cases studied, there would have been pre-existing low affinity Ab that would have probably created ICs and increased the valency of the reaction. These pioneering studies bear revisiting in light of what is now known about BCR signaling and FDCs in GCs.

Two, more recent, elegant studies have provided more support for the idea that strong crosslinking by $\mathrm{Ag}$ is a negative signal in the GC. Brink and colleagues engineered a pseudo-self Ag that would be bound by a responding B cell in the GC only if that B cell had a specific $\mathrm{V}$ region mutation ${ }^{169}$. Indeed, as predicted by the model, self-reactive mutants were selective censored in the GC even while anti-non-self mutants were positively selected. By expressing the pseudo-self $\mathrm{Ag}$ in different tissues they were able to infer that selftolerance in the $\mathrm{GC}$ required local expression (B cells expression was sufficient). These data complemented related work in which a pseudo-self Ag was expressed on FDC ${ }^{170}$, here demonstrating that it could enforce negative selection within the B cell follicle as even self- 
reactive NBC were either deleted or anergized. Presumably, this FDC-based expression of a pseudoself-Ag would mimic the situation where $\mathrm{Ag}$ is instead bound onto the FDC surface within an IC. This fits with the view, argued above, that Ag deposits on FDC are likely counterregulatory rather than stimulatory.

\section{Recent progress and future directions}

In this article we have detailed how the last six years have seen substantial progress in our understanding of the fundamental processes that govern GC function. While positive selection of higher affinity B cells has long been appreciated, new insights have revealed key transcription factors (e.g. c-Myc and FOXO1) that underpin the process, as well as the signals that link BCR and T cell-derived signals to their expression. These signals are rewired in the GC, and the mechanisms behind this are the subject of ongoing work. In addition, the microanatomic locations where positive selection occurs and how cells migrate in response to selecting signals in the GC have been elucidated. Our understanding of how proliferation and cell death result from either positive selection signals, failure of positive selection, or negative selection (i.e. "self-reactivity") has also advanced.

Because of the very small numbers of long-lived MBC and LLPC that are generated over the life of a GC compared to the total number of GCBC, it has been notoriously difficult to identify the putative precursors of such long-lived progeny within the GC, as well as to discern the signals that induce differentiation. With respect to MBC, we have seen advances in determining the timing of $\mathrm{MBC}$ formation, potential precursors within the $\mathrm{GC}$, signals that lead to $\mathrm{MBC}$ induction, transcription factor regulation associated with the transition from $\mathrm{GCBC}$ to $\mathrm{MBC}$, and how alteration of surface receptors may lead to GC exit. There has been less insight into LLPC formation, but again there has been progress that parallels that seen for MBC. Consensus on some of these issues is still pending, and more work is needed.

At the same time many open and exciting questions remain for the field to tackle. We would like a more full picture of how GCBC integrate $\mathrm{Ag}$ and $\mathrm{T}$ cell signals, including cytokine signals as well as cues from stromal cells and molecules such as integrins. This should extend from the GCBC-specific expression of surface receptors, to their remodeled cytoplasmic signaling networks, to the epigenetic landscape in GCBC. The goal is to understand how these GCBC-specific alterations then condition the response to environmental cues that ultimately yield results such as survival, proliferation and differentiation. A central question is how selection is so efficient, given all of the seemingly random events that underlie it, starting with the rather promiscuous effects of AID in creating the substrate for $\mathrm{V}$ region diversity. Certain results suggest that more fit clones may dominantly suppress less fit clones in the same GC, but this has not been directly proven. In addition, as noted, there are still many open questions about how MBC and PC differentiation are induced; in particular direct evidence is lacking for precursor-product relationships that have been proposed. Finally, all of the recent and rapid ongoing progress can be integrated into more accurate and detailed mathematical models, that integrate multiple aspects of GC development, a quest that is being pursued by multiple groups $42,54,126,171-173$. These can be highly useful in integrating diverse sets of data, highlighting 
areas that need further clarification, and providing insight into a complex and dynamic system that in many respects still remains a mystery.

\section{Acknowledgements:}

We thank our laboratory colleagues for many useful discussions and Danny Wikenheiser and Rebecca Elsner for critical reading of the manuscript. Supported by NIH grants 1R01 AI105018-05 and R01 AI043603-18 to MJS

\section{References}

1. Klein U, Tu Y, Stolovitzky GA, et al. Transcriptional analysis of the B cell germinal center reaction. Proc Natl Acad Sci U S A 2003;100(5):2639-2644. [PubMed: 12604779]

2. Velichutina I, Shaknovich R, Geng H, et al. EZH2-mediated epigenetic silencing in germinal center B cells contributes to proliferation and lymphomagenesis. Blood 2010;116(24):5247-5255. [PubMed: 20736451]

3. Hatzi K, Jiang Y, Huang C, et al. A hybrid mechanism of action for BCL6 in B cells defined by formation of functionally distinct complexes at enhancers and promoters. Cell reports 2013;4(3): 578-588. [PubMed: 23911289]

4. Ye BH, Cattoretti G, Shen Q, et al. The BCL-6 proto-oncogene controls germinal-centre formation and Th2- type inflammation. Nat Genet 1997;16(2):161-170. [PubMed: 9171827]

5. Nurieva RI, Chung Y, Hwang D, et al. Generation of T follicular helper cells is mediated by interleukin-21 but independent of T helper 1, 2, or 17 cell lineages. Immunity 2008;29(1):138-149. [PubMed: 18599325]

6. Crotty S Follicular helper CD4 T cells (TFH). Annual review of immunology 2011;29:621-663.

7. Weber JP, Fuhrmann F, Hutloff A. T-follicular helper cells survive as long-term memory cells. Eur J Immunol 2012;42(8):1981-1988. [PubMed: 22730020]

8. Hale JS, Youngblood B, Latner DR, et al. Distinct memory CD4+ T cells with commitment to T follicular helper- and T helper 1-cell lineages are generated after acute viral infection. Immunity 2013;38(4):805-817. [PubMed: 23583644]

9. Ise W, Inoue T, McLachlan JB, et al. Memory B cells contribute to rapid Bcl6 expression by memory follicular helper T cells. Proc Natl Acad Sci U S A 2014;111(32):11792-11797. [PubMed: 25071203]

10. Chung Y, Tanaka S, Chu F, et al. Follicular regulatory T cells expressing Foxp3 and Bcl-6 suppress germinal center reactions. Nature medicine 2011;17(8):983-988.

11. Linterman MA, Pierson W, Lee SK, et al. Foxp3(+) follicular regulatory T cells control the germinal center response. Nature medicine 2011;17(8):975-982.

12. Wollenberg I, Agua-Doce A, Hernandez A, et al. Regulation of the germinal center reaction by Foxp3+ follicular regulatory T cells. Journal of immunology 2011;187(9):4553-4560.

13. MacLennan IC. Germinal centers. Annu Rev Immunol 1994;12:117-139. [PubMed: 8011279]

14. Klaus GGB, Humphrey JH, Kunkl A, Dongworth DW. The follicular dendritic cell: Its role in antigen presentation in the generation of immunological memory. Immunol Rev 1980;53:3-28. [PubMed: 7009406]

15. Chang JE, Turley SJ. Stromal infrastructure of the lymph node and coordination of immunity. Trends in Immunology 2015;36(1):30-39. [PubMed: 25499856]

16. Wang X, Rodda LB, Bannard O, Cyster JG. Integrin-mediated interactions between B cells and follicular dendritic cells influence germinal center B cell fitness. J Immunol 2014;192(10):46014609. [PubMed: 24740506]

17. Cyster JG, Ansel KM, Reif K, et al. Follicular stromal cells and lymphocyte homing to follicles [In Process Citation]. Immunol Rev 2000;176:181-193. [PubMed: 11043777]

18. Cremasco V, Woodruff MC, Onder L, et al. B cell homeostasis and follicle confines are governed by fibroblastic reticular cells. Nature Immunology 2014;15:973. [PubMed: 25151489]

19. Reynes M, Aubert JP, Cohen JH, et al. Human follicular dendritic cells express CR1, CR2, and CR3 complement receptor antigens. J Immunol 1985;135(4):2687-2694. [PubMed: 2411809] 
20. Johnson GD, Hardie DL, Ling NR, MacLennan ICM. Human follicular dendritic cells (FDC): a study with monoclonal antibodies (MoAb). Clinical Experimental Immunology 1986;64:205-213. [PubMed: 3524917]

21. Kosco MH, Tew TG, Szakal AK. Antigenic phenotyping of isolated and in situ rodent follicular dendritic cells (FDC) with emphasis on the ultrastructural demonstration of Ia antigens. Anat Rec 1986;215:201-213. [PubMed: 3526978]

22. Kosco-Vilbois MH. Opinion: Are follicular dendritic cells really good for nothing? Nat Rev Immunol 2003;3(9):764-769. [PubMed: 12949500]

23. Bannard O, Horton Robert M, Allen Christopher DC, An J, Nagasawa T, Cyster Jason G. Germinal Center Centroblasts Transition to a Centrocyte Phenotype According to a Timed Program and Depend on the Dark Zone for Effective Selection. Immunity 2013;39(5):912-924. [PubMed: 24184055]

24. Rodda LB, Bannard O, Ludewig B, Nagasawa T, Cyster JG. Phenotypic and Morphological Properties of Germinal Center Dark Zone Cxcl12-Expressing Reticular Cells. J Immunol 2015;195(10):4781-4791. [PubMed: 26453751]

25. Jacob J, Kelsoe G, Rajewsky K, Weiss U. Intraclonal generation of antibody mutants in germinal centres. Nature 1991;354(6352):389-392. [PubMed: 1956400]

26. William J, Euler C, Christensen S, Shlomchik MJ. Evolution of autoantibody responses via somatic hypermutation outside of germinal centers. Science 2002;297:2066-2070. [PubMed: 12242446]

27. Di Niro R, Lee SJ, Vander Heiden JA, et al. Salmonella Infection Drives Promiscuous B Cell Activation Followed by Extrafollicular Affinity Maturation. Immunity 2015;43(1):120-131. [PubMed: 26187411]

28. Jacob J, Przylepa J, Miller C, Kelsoe G. In situ studies of the primary immune response to (4hydroxy-3-nitrophenyl)acetyl. III. The kinetics of $\mathrm{V}$ region mutation and selection in germinal center B cells. Journal of Experimental Medicine 1993;178(4):1293-1307. [PubMed: 8376935]

29. Tas JM, Mesin L, Pasqual G, et al. Visualizing antibody affinity maturation in germinal centers. Science 2016;351(6277):1048-1054. [PubMed: 26912368]

30. Shih TA, Meffre E, Roederer M, Nussenzweig MC. Role of BCR affinity in T cell dependent antibody responses in vivo. Nat Immunol 2002;3(6):570-575. [PubMed: 12021782]

31. Schwickert TA, Victora GD, Fooksman DR, et al. A dynamic T cell-limited checkpoint regulates affinity-dependent B cell entry into the germinal center. The Journal of experimental medicine 2011;208(6):1243-1252. [PubMed: 21576382]

32. Adachi Y, Onodera T, Yamada Y, et al. Distinct germinal center selection at local sites shapes memory B cell response to viral escape. The Journal of Experimental Medicine 2015;212(10): 1709-1723. [PubMed: 26324444]

33. Zuccarino-Catania GV, Sadanand S, Weisel FJ, et al. CD80 and PD-L2 define functionally distinct memory B cell subsets that are independent of antibody isotype. Nat Immunol 2014;15(7):631637. [PubMed: 24880458]

34. Allen CD, Okada T, Tang HL, Cyster JG. Imaging of Germinal Center Selection Events During Affinity Maturation. Science 2006.

35. Hauser AE, Junt T, Mempel TR, et al. Definition of germinal-center B cell migration in vivo reveals predominant intrazonal circulation patterns. Immunity 2007;26(5):655-667. [PubMed: 17509908]

36. Mayer CT, Gazumyan A, Kara EE, et al. The microanatomic segregation of selection by apoptosis in the germinal center. Science 2017;358(6360).

37. Muramatsu M, Sankaranand VS, Anant S, et al. Specific Expression of Activation-induced Cytidine Deaminase (AID), a Novel Member of the RNA-editing Deaminase Family in Germinal Center B Cells. Journal of Biological Chemistry 1999;274(26):18470-18476. [PubMed: 10373455]

38. Cattoretti G, Büttner M, Shaknovich R, Kremmer E, Alobeid B, Niedobitek G. Nuclear and cytoplasmic AID in extrafollicular and germinal center B cells. Blood 2006;107(10):3967-3975. [PubMed: 16439679] 
39. Muramatsu M, Kinoshita K, Fagarasan S, Yamada S, Shinkai Y, Honjo T. Class switch recombination and hypermutation require activation-induced cytidine deaminase (AID), a potential RNA editing enzyme. Cell 2000;102(5):553-563. [PubMed: 11007474]

40. Clarke SH, Huppi K, Ruezinsky D, Staudt L, Gerhard W, Weigert M. Inter- and intraclonal diversity in the antibody response to influenza hemagglutinin. J Exp Med 1985;161:687-704. [PubMed: 3920342]

41. McKean D, Huppi K, Bell M, Straudt L, Gerhard W, Weigert M. Generation of antibody diversity in the immune response of BALB/c mice to influenza virus hemagglutinin. Proceedings of the National Academy of Science 1984;81:3180-3184.

42. Anderson SM, Khalil A, Uduman M, et al. Taking advantage: high-affinity B cells in the germinal center have lower death rates, but similar rates of division, compared to low-affinity cells. $\mathbf{J}$ Immunol 2009;183(11):7314-7325. [PubMed: 19917681]

43. Shlomchik MJ, Aucoin AH, Pisetsky DS, Weigert MG. Structure and function af anti-DNA antibodies derived from a single autoimmune mouse. Proc Natl Acad Sci 1987;84:9150-9154. [PubMed: 3480535]

44. Shlomchik MJ, Litwin S, Weigert M. The influence of somatic mutation on clonal expansion. Prog Immunol Proc 7th Int Cong Immunol 1990;7:415-423.

45. Weisel FJ, Zuccarino-Catania GV, Chikina M, Shlomchik MJ. A Temporal Switch in the Germinal Center Determines Differential Output of Memory B and Plasma Cells. Immunity 2016;44(1): 116-130. [PubMed: 26795247]

46. MacLennan ICM. From the dark zone to the light. Curr Biology 1994;4:70-72.

47. Camacho SA, Kosco-Vilbois MH, Berek C. The dynamic structure of the germinal center. Immunol Today 1998;19(11):511-514. [PubMed: 9818545]

48. Gitlin AD, Shulman Z, Nussenzweig MC. Clonal selection in the germinal centre by regulated proliferation and hypermutation. Nature 2014;509:637. [PubMed: 24805232]

49. Wittenbrink N, Klein A, Weiser AA, Schuchhardt J, Or-Guil M. Is There a Typical Germinal Center? A Large-Scale Immunohistological Study on the Cellular Composition of Germinal Centers during the Hapten-Carrier, Äìriven Primary Immune Response in Mice. The Journal of Immunology 2011;187(12):6185-6196. [PubMed: 22102720]

50. Kepler TB, Perelson AS. Cyclic re-entry of germinal center B cells and the efficiency of affinity maturation. Immunol Today 1993;14:412-414. [PubMed: 8397781]

51. Kepler TB, Perelson AS. Somatic hypermutation in B cells: an optimal control treatment. J Theor Biol 1993;164(1):37-64. [PubMed: 8264243]

52. Radmacher MD, Kelsoe G, Kepler TB. Predicted and inferred waiting times for key mutations in the germinal centre reaction: evidence for stochasticity in selection. Immunol Cell Biol 1998;76(4):373-381. [PubMed: 9723780]

53. Meyer-Hermann M Does recycling in germinal centres exist? Immunol Cell Biol 2002;80(1):30_ 35. [PubMed: 11869360]

54. Meyer-Hermann M, Mohr E, Pelletier N, Zhang Y, Victora GD, Toellner KM. A theory of germinal center B cell selection, division, and exit. Cell reports 2012;2(1):162-174. [PubMed: 22840406]

55. Hauser AE, Shlomchik MJ, Haberman AM. In vivo imaging studies shed light on germinal-centre development. Nat Rev Immunol 2007;7(7):499-504. [PubMed: 17589541]

56. Allen CD, Okada T, Cyster JG. Germinal-center organization and cellular dynamics. Immunity 2007;27(2):190-202. [PubMed: 17723214]

57. Schwickert TA, Lindquist RL, Shakhar G, et al. In vivo imaging of germinal centres reveals a dynamic open structure. Nature 2007;446(7131):83-87. [PubMed: 17268470]

58. Victora GD, Schwickert TA, Fooksman DR, et al. Germinal center dynamics revealed by multiphoton microscopy with a photoactivatable fluorescent reporter. Cell 2010;143(4):592-605. [PubMed: 21074050]

59. McDevitt HO, Askonas BA, Humphrey JH, Schecter I, Sela M. The localization of antigen in relation to specific antibody-producing cells 1 . Use of a synthetic polypeptide [(T,G)-A--L] labelled with iodine-125. Immunology 1966;11:337-351. [PubMed: 5924619]

60. Nossal GJV, Ada GL, Austin CM, Pye J. Antigens in immunity VIII. localization of 125I-labelled antigens in the secondary response. Immunology 1965;9:349-357. [PubMed: 5844810] 
61. Nossal GJV, Abbot A, Mitchell J, Lummus Z. Antigens in immunity. XV. Ultrastructural features of antigen capture in primary and secondary lymphoid follicles. J Exp Med 1968;127:277. [PubMed: 4169585]

62. Tew JG, Phipps RP, Madnel TE. The follicular dendritic cell: long-term antigen retention during immunity. Immunol Rev 1980;53:29. [PubMed: 6162778]

63. Schnizlein CT, Kosco MH, Szakal AK, Tew JG. Follicular dendritic cells in suspension: identification, enrichment, and initial characterization indicating immune complex trapping and lack of adherence and phagocytic activity. Journal of Immunology 1985;134(3):1360-1368.

64. Szakal A, Kosco M, Tew J. FDC-iccosome mediated antigen delivery to germinal center B cells, antigen processing and presentation to T cells. Advances in Experimental Medicine \& Biology 1988;237(197):197-202. [PubMed: 3267045]

65. Tew JG, Wu J, Qin D, Helm S, Burton GF, Szakal AK. Follicular dendritic cells and presentation of antigen and costimulatory signals to B cells. Immunol Rev 1997;156:39-52. [PubMed: 9176698]

66. Qin D, Wu J, Carroll MC, Burton GF, Szakal AK, Tew JG. Evidence for an important interaction between a complement-derived CD21 ligand on follicular dendritic cells and CD21 on B cells in the initiation of IgG responses. J Immunol 1998;161(9):4549-4554. [PubMed: 9794381]

67. Qin D, Wu J, Vora KA, et al. Fcgamma receptor IIB on follicular dendritic cells regulates the B cell recall response [In Process Citation]. J Immunol 2000;164(12):6268-6275. [PubMed: 10843680]

68. Reynes M, Aubert JP, Cohen JHM, et al. Human follicular dendritic cells express CR1, CR2, and CR3 complement receptor antigens. J Immunol 1985;135(4):2687-2694. [PubMed: 2411809]

69. Gonzalez SF, Pitcher LA, Mempel T, Schuerpf F, Carroll MC. B cell acquisition of antigen in vivo. [Review] [46 refs]. Current Opinion in Immunology 2009;21(3):251-257. [PubMed: 19515546]

70. Roozendaal R, Mempel TR, Pitcher LA, et al. Conduits mediate transport of low-molecular-weight antigen to lymph node follicles. Immunity 2009;30(2):264-276. [PubMed: 19185517]

71. Pape KA, Catron DM, Itano AA, Jenkins MK. The humoral immune response is initiated in lymph nodes by B cells that acquire soluble antigen directly in the follicles. Immunity 2007;26(4):491502. [PubMed: 17379546]

72. Attanavanich K, Kearney JF. Marginal zone, but not follicular B cells, are potent activators of naive CD4 T cells. J Immunol 2004;172(2):803-811. [PubMed: 14707050]

73. Luo W, Weisel F, Shlomchik MJ. B Cell Receptor and CD40 Signaling Are Rewired for Synergistic Induction of the c-Myc Transcription Factor in Germinal Center B Cells. Immunity 2018;48(2):313-326 e315. [PubMed: 29396161]

74. You Y, Myers RC, Freeberg L, et al. Marginal zone B cells regulate antigen capture by marginal zone macrophages. J Immunol 2011;186.

75. Phan TG, Grigorova I, Okada T, Cyster JG. Subcapsular encounter and complement-dependent transport of immune complexes by lymph node B cells. Nat Immunol 2007;8(9):992-1000. [PubMed: 17660822]

76. Cinamon G, Zachariah MA, Lam OM, Foss FW, Cyster JG. Follicular shuttling of marginal zone B cells facilitates antigen transport. Nat Immunol 2008;9. [PubMed: 18087248]

77. Suzuki K, Grigorova I, Phan TG, Kelly LM, Cyster JG. Visualizing B cell capture of cognate antigen from follicular dendritic cells. J Exp Med 2009;206(7):1485-1493. [PubMed: 19506051]

78. Gonzalez SF, Lukacs-Kornek V, Kuligowski MP, et al. Complement-Dependent Transport of Antigen into B Cell Follicles. The Journal of Immunology 2010;185(5):2659-2664. [PubMed: 20724732]

79. Heesters BA, Myers RC, Carroll MC. Follicular dendritic cells: dynamic antigen libraries. Nat Rev Immunol 2014;14(7):495-504. [PubMed: 24948364]

80. Batista FD, Harwood NE. The who, how and where of antigen presentation to B cells. Nat Rev Immunol 2009;9(1):15-27. [PubMed: 19079135]

81. Hannum LG, Haberman AM, Anderson SM, Shlomchik MJ. Germinal center initiation, variable gene region hypermutation, and mutant $\mathrm{B}$ cell selection without detectable immune complexes on follicular dendritic cells. J Exp Med 2000;192(7):931-942. [PubMed: 11015435] 
82. Vora KA, Ravetch JV, Manser T. Amplified follicular immune complex deposition in mice lacking the Fc receptor g-chain does not alter maturation of the B cell response. J Immunol 1997;159:2116-2124. [PubMed: 9278297]

83. Rao SP, Vora KA, Manser T. Differential expression of the inhibitory IgG Fc receptor FcgammaRIIB on germinal center cells: implications for selection of high-affinity B cells. J Immunol 2002;169(4):1859-1868. [PubMed: 12165510]

84. Simmons WJ, Simms M, Chiarle R, et al. Induction of germinal centers by MMTV encoded superantigen on B cells. Dev Immunol 2001;8(3-4):201-211. [PubMed: 11785670]

85. Ahearn JM, Fischer MB, Croix D, et al. Disruption of the Cr2 locus results in a reduction in B-1a cells and in an impaired B cell response to T-dependent antigen. Immunity 1996;4:251-262. [PubMed: 8624815]

86. Chen Z, Koralov SB, Kelsoe G. Regulation of humoral immune responses by CD21/CD35. Immunol Rev 2000;176:194-204. [PubMed: 11043778]

87. Rossbacher J, Haberman AM, Neschen S, Khalil A, Shlomchik MJ. Antibody-independent B cellintrinsic and -extrinsic roles for CD21/35. Eur J Immunol 2006;36(9):2384-2393. [PubMed: 16906534]

88. Rossbacher J, Shlomchik MJ. The B cell receptor itself can activate complement to provide the complement receptor $1 / 2$ ligand required to enhance B cell immune responses in vivo. J Exp Med 2003;198(4):591-602. [PubMed: 12925675]

89. Ohishi K, Kanoh M, Shinomiya H, Hitsumoto Y, Utsumi S. Complement activation by cross-linked B cell-membrane IgM. J Immunol 1995;154:3173-3179. [PubMed: 7897206]

90. Vinuesa CG, Linterman MA, Goodnow CC, Randall KL. T cells and follicular dendritic cells in germinal center B-cell formation and selection 2010;237(1):72-89.

91. Mesin L, Ersching J, Victora GD. Germinal Center B Cell Dynamics. Immunity 2016;45(3):471482. [PubMed: 27653600]

92. Zhang Y, Garcia-Ibanez L, Toellner K-M. Regulation of germinal center B-cell differentiation. Immunological Rev 2016;270(1):8-19.

93. Haberman AM, Shlomchik MJ. Reassessing the function of immune-complex retention by follicular dendritic cells. Nat Rev Immunol 2003;3(9):757-764. [PubMed: 12949499]

94. Rahman ZS, Manser T. Failed up-regulation of the inhibitory IgG Fc receptor Fc gamma RIIB on germinal center B cells in autoimmune-prone mice is not associated with deletion polymorphisms in the promoter region of the Fc gamma RIIB gene. J Immunol 2005;175(3):1440-1449. [PubMed: 16034080]

95. Tiller T, Kofer J, Kreschel C, et al. Development of self-reactive germinal center B cells and plasma cells in autoimmune Fc gammaRIIB-deficient mice. J Exp Med 2010;207(12):2767-2778. [PubMed: 21078890]

96. Khalil AM, Cambier JC, Shlomchik MJ. B Cell Receptor Signal Transduction in the GC Is ShortCircuited by High Phosphatase Activity. Science 2012;336(6085):1178-1181. [PubMed: 22555432]

97. He JS, Meyer-Hermann M, Deng XY, et al. The distinctive germinal center phase of $\operatorname{IgE}(+)$ B lymphocytes limits their contribution to the classical memory response. Journal of Experimental Medicine 2013;210(12):2755-2771. [PubMed: 24218137]

98. Mueller J, Matloubian M, Zikherman J. Cutting edge: An in vivo reporter reveals active B cell receptor signaling in the germinal center. J Immunol 2015;194(7):2993-2997. [PubMed: 25725108]

99. Nowosad CR, Spillane KM, Tolar P. Germinal center B cells recognize antigen through a specialized immune synapse architecture. Nat Immunol 2016;17(7):870-877. [PubMed: 27183103]

100. Liu D, Xu H, Shih C, et al. T-B-cell entanglement and ICOSL-driven feed-forward regulation of germinal centre reaction. Nature 2015;517(7533):214-218. [PubMed: 25317561]

101. Shimoda M, Li T, Pihkala JP, Koni PA. Role of MHC class II on memory B cells in post-germinal center B cell homeostasis and memory response. J Immunol 2006;176(4):2122-2133. [PubMed: 16455968] 
102. Han S, Hathcock K, Zheng B, Kepler TB, Hodes R, Kelsoe G. Cellular interaction in germinal centers. Roles of CD40 ligand and B7-2 in established germinal centers. J Immunol 1995;155(2): 556-567. [PubMed: 7541819]

103. Zotos D, Coquet JM, Zhang Y, et al. IL-21 regulates germinal center B cell differentiation and proliferation through a B cell-intrinsic mechanism. J Exp Med 2010;207(2):365-378. [PubMed: 20142430]

104. Chevrier S, Kratina T, Emslie D, Tarlinton DM, Corcoran LM. IL4 and IL21 cooperate to induce the high Bcl6 protein level required for germinal center formation. Immunol Cell Biol 2017;95(10):925-932. [PubMed: 28875978]

105. McGuire HM, Vogelzang A, Warren J, et al. IL-21 and IL-4 Collaborate To Shape T-Dependent Antibody Responses 2015.

106. Zaretsky I, Atrakchi O, Mazor RD, et al. ICAMs support B cell interactions with T follicular helper cells and promote clonal selection. J Exp Med 2017;214(11):3435-3448. [PubMed: 28939548]

107. Dominguez-Sola D, Victora GD, Ying CY, et al. The proto-oncogene MYC is required for selection in the germinal center and cyclic reentry. Nat Immunol 2012;13(11):1083-1091. [PubMed: 23001145]

108. Calado DP, Sasaki Y, Godinho SA, et al. The cell-cycle regulator c-Myc is essential for the formation and maintenance of germinal centers. Nat Immunol 2012;13(11):1092-1100. [PubMed: 23001146]

109. Ersching J, Efeyan A, Mesin L, et al. Germinal Center Selection and Affinity Maturation Require Dynamic Regulation of mTORC1 Kinase. Immunity 2017;46(6):1045-1058 e1046. [PubMed: 28636954]

110. Shih C, Qi H. Intravital Microscopy of T-B Cell Interactions in Germinal Centers. Methods Mol Biol 2017;1623:73-85. [PubMed: 28589348]

111. Yusuf I, Zhu X, Kharas MG, Chen J, Fruman DA. Optimal B-cell proliferation requires phosphoinositide 3-kinase-dependent inactivation of FOXO transcription factors. Blood 2004;104(3):784-787. [PubMed: 15069012]

112. Jacinto E, Facchinetti V, Liu D, et al. SIN1/MIP1 maintains rictor-mTOR complex integrity and regulates Akt phosphorylation and substrate specificity. Cell 2006;127(1):125-137. [PubMed: 16962653]

113. Sander S, Chu VT, Yasuda T, et al. PI3 Kinase and FOXO1 Transcription Factor Activity Differentially Control B Cells in the Germinal Center Light and Dark Zones. Immunity 2015;43(6):1075-1086. [PubMed: 26620760]

114. Dominguez-Sola D, Kung J, Holmes AB, et al. The FOXO1 Transcription Factor Instructs the Germinal Center Dark Zone Program. Immunity 2015;43(6):1064-1074. [PubMed: 26620759]

115. Inoue T, Shinnakasu R, Ise W, Kawai C, Egawa T, Kurosaki T. The transcription factor Foxo1 controls germinal center B cell proliferation in response to T cell help 2017;214(4):1181-1198.

116. Wilhelm K, Happel K, Eelen G, et al. FOXO1 couples metabolic activity and growth state in the vascular endothelium. Nature 2016;529(7585):216-220. [PubMed: 26735015]

117. Duyao MP, Buckler AJ, Sonenshein GE. Interaction of an NF-kappa B-like factor with a site upstream of the c-myc promoter 1990;87(12):4727-4731.

118. La Rosa FA, Pierce JW, Sonenshein GE. Differential regulation of the c-myc oncogene promoter by the NF-kappa B rel family of transcription factors 1994;14(2):1039-1044.

119. Wang P, Shih CM, Qi H, Lan YH. A Stochastic Model of the Germinal Center Integrating Local Antigen Competition, Individualistic T-B Interactions, and B Cell Receptor Signaling. J Immunol 2016;197(4):1169-1182. [PubMed: 27421481]

120. Liu YJ, Mason DY, Johnson GD, et al. Germinal center cells express bcl-2 protein after activation by signals which prevent their entry into apoptosis. European Journal of Immunology 1991;21(8):1905-1910. [PubMed: 1868875]

121. Tuscano JM, Druey KM, Riva A, Pena J, Thompson CB, Kehrl JH. Bcl-x rather than Bcl-2 mediates CD40-dependent centrocyte survival in the germinal center. Blood 1996;88:1359-1364. [PubMed: 8695854] 
122. Vikstrom I, Carotta S, Luthje K, et al. Mcl-1 is essential for germinal center formation and B cell memory. Science 2010;330(6007):1095-1099. [PubMed: 20929728]

123. Heinzel S, Binh Giang T, Kan A, et al. A Myc-dependent division timer complements a cell-death timer to regulate T cell and B cell responses. Nat Immunol 2017;18(1):96-103. [PubMed: 27820810]

124. Gitlin AD, Mayer CT, Oliveira TY, et al. HUMORAL IMMUNITY. T cell help controls the speed of the cell cycle in germinal center B cells. Science 2015;349(6248):643-646. [PubMed: 26184917]

125. Shlomchik MJ, Watts P, Weigert MG, Litwin S. Clone: a Monte-Carlo computer simulation of B cell clonal expansion, somatic mutation, and antigen-driven selection. Curr Top Microbiol Immunol 1998;229:173-197. [PubMed: 9479855]

126. Meyer-Hermann M Overcoming the dichotomy of quantity and quality in antibody responses. $\mathrm{J}$ Immunol 2014;193(11):5414-5419. [PubMed: 25355924]

127. Dal Porto JM, Haberman AM, Kelsoe G, Shlomchik MJ. Very low affinity B cells form germinal centers, become memory B cells, and participate in secondary immune responses when higher affinity competition is reduced. J Exp Med 2002;195(9):1215-1221. [PubMed: 11994427]

128. Zhang Y, Meyer-Hermann M, George LA, et al. Germinal center B cells govern their own fate via antibody feedback. J Exp Med 2013;210(3):457-464. [PubMed: 23420879]

129. Kelsoe G, Zheng B. Sites of B-cell activation in vivo. [Review]. Current Opinion in Immunology 1993;5(3):418-422. [PubMed: 8347301]

130. Dal Porto JM, Haberman AM, Shlomchik MJ, Kelsoe G. Antigen drives very low affinity B cells to become plasmacytes and enter germinal centers. J Immunol 1998;161(10):5373-5381. [PubMed: 9820511]

131. Qi H, Chen X, Chu C, Lu P, Xu H, Yan J. Follicular T-helper cells: controlled localization and cellular interactions. Immunol Cell Biol 2014;92(1):28-33. [PubMed: 24145857]

132. Boulianne B, Rojas OL, Haddad D, et al. AID and caspase 8 shape the germinal center response through apoptosis. J Immunol 2013;191(12):5840-5847. [PubMed: 24244021]

133. Berek C, Berger A, Apel M. Maturation of the immune response in germinal centers. Cell 1991;67(6):1121-1129. [PubMed: 1760840]

134. Victora Gabriel D, Wilson Patrick C. Germinal Center Selection and the Antibody Response to Influenza. Cell 2015;163(3):545-548. [PubMed: 26496601]

135. Wrammert J, Koutsonanos D, Li GM, et al. Broadly cross-reactive antibodies dominate the human B cell response against 2009 pandemic H1N1 influenza virus infection. J Exp Med 2011;208(1):181-193. [PubMed: 21220454]

136. Wrammert J, Smith K, Miller J, et al. Rapid cloning of high-affinity human monoclonal antibodies against influenza virus. Nature 2008;453(7195):667-671. [PubMed: 18449194]

137. Kuraoka M, Schmidt AG, Nojima T, et al. Complex Antigens Drive Permissive Clonal Selection in Germinal Centers. Immunity 2016;44(3):542-552. [PubMed: 26948373]

138. Inamine A, Takahashi Y, Baba N, et al. Two waves of memory B-cell generation in the primary immune response. Int Immunol 2005;17(5):581-589. [PubMed: 15824068]

139. Takemori T, Kaji T, Takahashi Y, Shimoda M, Rajewsky K. Generation of memory B cells inside and outside germinal centers. European Journal of Immunology 2014;44(5):1258-1264. [PubMed: 24610726]

140. Anderson SM, Tomayko MM, Ahuja A, Haberman AM, Shlomchik MJ. New markers for murine memory B cells that define mutated and unmutated subsets. J Exp Med 2007;204(9):2103-2114. [PubMed: 17698588]

141. Taylor JJ, Pape KA, Jenkins MK. A germinal center-independent pathway generates unswitched memory B cells early in the primary response. J Exp Med 2012;209(3):597-606. [PubMed: 22370719]

142. Shinnakasu R, Inoue T, Kometani K, et al. Regulated selection of germinal-center cells into the memory B cell compartment. Nat Immunol 2016;17(7):861-869. [PubMed: 27158841]

143. Kometani K, Nakagawa R, Shinnakasu R, et al. Repression of the transcription factor Bach2 contributes to predisposition of IgG1 memory B cells toward plasma cell differentiation. Immunity 2013;39(1):136-147. [PubMed: 23850379] 
144. Wang Y, Shi J, Yan J, et al. Germinal-center development of memory B cells driven by IL-9 from follicular helper T cells. Nat Immunol 2017;18(8):921-930. [PubMed: 28650481]

145. Takatsuka S, Yamada H, Haniuda K, et al. IL-9 receptor signaling in memory B cells regulates humoral recall responses. Nat Immunol 2018;19(9):1025-1034. [PubMed: 30082831]

146. Laidlaw BJ, Schmidt TH, Green JA, Allen CD, Okada T, Cyster JG. The Eph-related tyrosine kinase ligand Ephrin-B1 marks germinal center and memory precursor B cells. J Exp Med 2017;214(3):639-649. [PubMed: 28143955]

147. Suan D, Krautler NJ, Maag JLV, et al. CCR6 Defines Memory B Cell Precursors in Mouse and Human Germinal Centers, Revealing Light-Zone Location and Predominant Low Antigen Affinity. Immunity 2017;47(6):1142-1153 e1144. [PubMed: 29262350]

148. Pape KA, Taylor JJ, Maul RW, Gearhart PJ, Jenkins MK. Different B cell populations mediate early and late memory during an endogenous immune response. Science 2011;331(6021):12031207. [PubMed: 21310965]

149. Takahashi Y, Ohta H, Takemori T. Fas is required for clonal selection in germinal centers and the subsequent establishment of the memory B cell repertoire. Immunity 2001;14(2):181-192. [PubMed: 11239450]

150. Tomayko MM, Steinel NC, Anderson SM, Shlomchik MJ. Cutting edge: Hierarchy of maturity of murine memory B cell subsets. J Immunol 2010;185(12):7146-7150. [PubMed: 21078902]

151. Weisel FJ, Appelt UK, Schneider AM, et al. Unique requirements for reactivation of virusspecific memory B lymphocytes. J Immunol 2010;185(7):4011-4021. [PubMed: 20739675]

152. Angelin-Duclos C, Cattoretti G, Lin KI, Calame K. Commitment of B lymphocytes to a plasma cell fate is associated with Blimp-1 expression in vivo. J Immunol 2000;165(10):5462-5471. [PubMed: 11067898]

153. Oracki SA, Walker JA, Hibbs ML, Corcoran LM, Tarlinton DM. Plasma cell development and survival. Immunological Rev 2010;237(1):140-159.

154. Blink EJ, Light A, Kallies A, Nutt SL, Hodgkin PD, Tarlinton DM. Early appearance of germinal center-derived memory B cells and plasma cells in blood after primary immunization. J Exp Med 2005;201(4):545-554. [PubMed: 15710653]

155. Kräutler NJ, Suan D, Butt D, et al. Differentiation of germinal center B cells into plasma cells is initiated by high-affinity antigen and completed by Tfh cells. The Journal of Experimental Medicine 2017.

156. Paus D, Phan TG, Chan TD, Gardam S, Basten A, Brink R. Antigen recognition strength regulates the choice between extrafollicular plasma cell and germinal center B cell differentiation. J Exp Med 2006;203(4):1081-1091. [PubMed: 16606676]

157. Phan TG, Paus D, Chan TD, et al. High affinity germinal center B cells are actively selected into the plasma cell compartment. J Exp Med 2006;203(11):2419-2424. [PubMed: 17030950]

158. Chan TD, Gatto D, Wood K, Camidge T, Basten A, Brink R. Antigen affinity controls rapid Tdependent antibody production by driving the expansion rather than the differentiation or extrafollicular migration of early plasmablasts. J Immunol 2009;183(5):3139-3149. [PubMed: 19666691]

159. Zhang Y, Tech L, George LA, et al. Plasma cell output from germinal centers is regulated by signals from Tfh and stromal cells. The Journal of Experimental Medicine 2018;215(4):12271243. [PubMed: 29549115]

160. Ise W, Fujii K, Shiroguchi K, et al. T Follicular Helper Cell-Germinal Center B Cell Interaction Strength Regulates Entry into Plasma Cell or Recycling Germinal Center Cell Fate. Immunity 2018;48(4):702-715 e704. [PubMed: 29669250]

161. Diamond B, Scharff MD. Somatic mutation of the T15 heavy chain gives rise to an antibody with autoantibody specificity. Proceedings of the National Academy of Science 1984;81:5841-5844.

162. Radic MZ, Mascelli MA, Erikson J, Shan H, Shlomchik M, Weigert M. Structural patterns in anti-DNA antibodies from MRL/lpr mice. Cold Spring Harb Symp Quant Biol 1989;54(Pt 2): 933-946. [PubMed: 2640629]

163. Radic MZ, Mackle J, Erikson J, Mol C, Anderson WF, Weigert M. Residues that mediate DNA binding of autoimmune antibodies. J Immunol 1993;150(11):4966-4967. [PubMed: 8496598] 
164. Tiller T, Tsuiji M, Yurasov S, Velinzon K, Nussenzweig MC, Wardemann H. Autoreactivity in human IgG+ memory B cells. Immunity 2007;26(2):205-213. [PubMed: 17306569]

165. Han S, Zheng B, Dal Porto J, Kelsoe G. In situ studies of the primary immune response to (4hydroxy-3-nitrophenyl)acetyl. IV. Affinity-dependent, antigen-driven B cell apoptosis in germinal centers as a mechanism for maintaining self-tolerance. J Exp Med 1995;182(6):16351644. [PubMed: 7500008]

166. Pulendran B, Kannourakis G, Nouri S, Smith KGC, Nossal GJV. Soluble-Antigen Can Cause Enhanced Apoptosis of Germinal-Center B-Cells. Nature 1995;375(6529):331-334. [PubMed: 7753199]

167. Shokat KM, Goodnow CC. Antigen-induced B-cell death and elimination during germinal-centre immune responses. Nature 1995;375(6529):334-338. [PubMed: 7753200]

168. Silva M, Nguyen TH, Philbrook P, et al. Targeted Elimination of Immunodominant B Cells Drives the Germinal Center Reaction toward Subdominant Epitopes. Cell reports 2017;21(13):36723680. [PubMed: 29281817]

169. Chan TD, Wood K, Hermes JR, et al. Elimination of germinal-center-derived self-reactive B cells is governed by the location and concentration of self-antigen. Immunity 2012;37(5):893-904. [PubMed: 23142780]

170. Yau IW, Cato MH, Jellusova J, Hurtado de Mendoza T, Brink R, Rickert RC. Censoring of selfreactive B cells by follicular dendritic cell-displayed self-antigen. J Immunol 2013;191(3):10821090. [PubMed: 23817432]

171. Singh H, Khan AA, Dinner AR. Gene regulatory networks in the immune system. Trends in Immunology 2014;35(5):211-218. [PubMed: 24768519]

172. Childs LM, Baskerville EB, Cobey S. Trade-offs in antibody repertoires to complex antigens 2015;370(1676).

173. Wittenbrink N, Weber TS, Klein A, et al. Broad Volume Distributions Indicate Nonsynchronized Growth and Suggest Sudden Collapses of Germinal Center B Cell Populations. J Immunol 2010. 


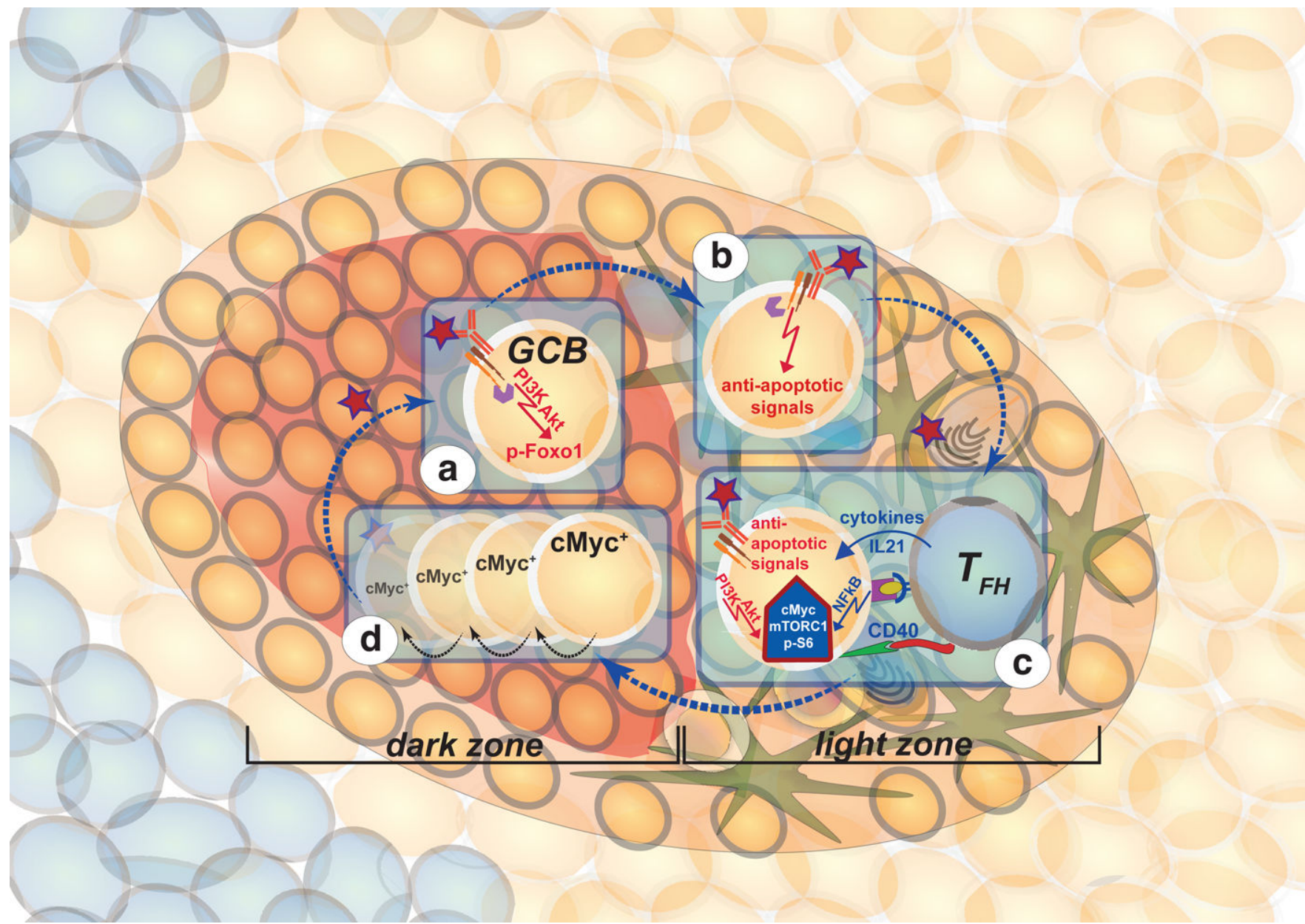

Fig. 1: Hybrid Model of GCBC Selection

Successful competition for antigen binding of dark zone GCBCs with are of sufficient affinity results in the generation of p-foxo1 through BCR mediated PI3K/Akt signaling (a) which promotes initial migration of these cells and "licenses" them to remain in the light zone. Additionally, BCR signaling may induce anti-apoptotic factors (b) which allow more time for the partly selected GCBCs to productively interact with cognate $\mathrm{T}_{\mathrm{FH}}$ cells. Upon such interaction, BCR and CD40 signaling synergistically lead to the expression of c-Myc and the activation of the mTORC1 pathway which induces the phosphorylation of S6, therefore fully engaging the process of positive selection (c). Positively selected LZ GCBCs migrate towards the DZ and their induced mTORC1-driven anabolic state readies them for intensive proliferation, which coincides with the acquisition of additional mutations catalyzed by AID. As c-Myc protein levels are diluted out with each cell division (d) DZ GCBCs need to be successful in binding to antigen in order to undergo another cycle of selection. Proliferating DZ GCBCs that fail to bind to antigen due to mutation-mediated reduced BCR affinity or function will undergo apoptosis. 